\title{
Steuerrückstellungen bei Regressandrohung nur mit Einschränkungen
}

\begin{abstract}
- Nach einem Urteil des Finanzgerichts Bremen dürfen Ärzte Rückstellungen für Regressforderungen der Krankenkassen wegen unwirtschaftlicher Verordnungsweise bilden, allerdings erst dann, wenn die Prüfgremien einen Regressbescheid erlassen haben. Zur steuerlichen Rückstellungsbildung reicht es nicht, dass mitgeteilt wird, dass die Richtgrößen für das Verordnungsvolumen überschritten wurden. Ebenso wenig genügt die Einleitung eines Verfahrens durch die Prüfgremien.
\end{abstract}

\section{MMW Kommentar}

Gegen eine Gemeinschaftspraxis wurde ein Prüfverfahren wegen Richtgrößenüberschreitung in mehreren Quartalen eingeleitet. In ihren Bilanzen hatten die Ärzte daraufhin gewinnmindernde Rückstellungen wegen der drohenden Regresse gebildet. Die Prüfverfahren wurden allerdings abgeschlossen, ohne dass es zu einer Inanspruchnahme der Rückstellungen kam. Das Finanzgericht hat dazu entschieden, dass eine solche Rückstellung erst gebildet werden darf, wenn am Bilanzstichtag ein Regressbescheid und damit eine unmittelbare Regressbedrohung vorliegt. Dies ist insofern positiv zu werten, als ja neben der steuerlichen Maßnahme noch die Möglichkeit besteht, den Regress abzuwenden. Beachtenswert ist auch folgendes Urteil des Bundessozialgerichts: Das BSG hat einen Regress wegen unwirtschaftlicher Verordnungsweise für Heilmittel trotz unterdurchschnittlicher Fallzahl für rechtmäßig erklärt. Der Vergleich mit der Fachgruppe, wie ihn der Beschwerdeausschuss vorgenommen hatte, sei trotz unterdurchschnittlicher Fallzahlen der Praxis nicht zu beanstanden. Selbst der Ein-

\section{Wird nun die Praxisabgabe an ausländische Ärzte möglich?}

- Ausländischen Fachkräften wie z. B. Ärzten ist die Einwanderung nach Deutschland deutlich erleichtert worden. Hinter-

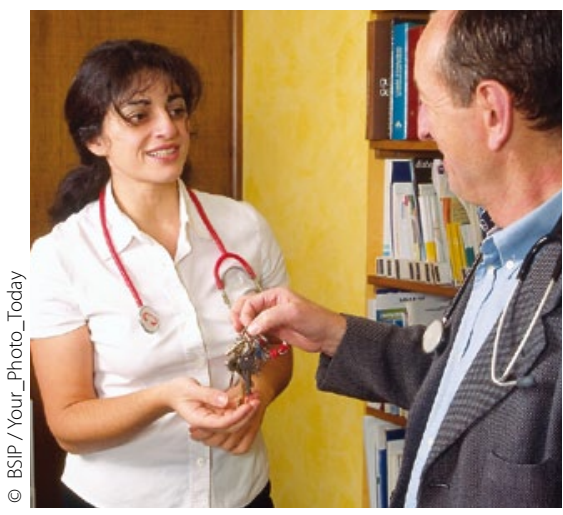

In anderen Ländern ausgebildete Ärzte sollen leichter in der BRD arbeiten können. grund ist die Einführung der sog. „Blauen Karte EU“ speziell für Hochqualifizierte. Die Karte kann von Ausländern genutzt werden, die einen Hochschulabschluss oder eine vergleichbare Qualifikation besitzen. Sie müssen zudem ein Arbeitsverhältnis nachweisen, das ein Bruttogehalt von mindestens 44800 Euro einbringt. Für Mangelberufe wie Ärzte beträgt die Gehaltsgrenze knapp 35000 Euro pro Jahr. Besteht ein solcher Arbeitsvertrag nach drei Jahren fort, erhalten die Inhaber der „Blauen Karte EU“ eine unbefristete Niederlassungserlaubnis, bei guten Deutschkenntnissen bereits nach zwei Jahren. Ausländer, die einen Hochschulabschluss haben und eigenständig ihren Lebensunterhalt sichern können, dürfen sechs Monate lang auf Arbeitsplatzsuche wand des Arztes, er habe in jedem Einzelfall die Frequenzvorgaben der Heilmittel-Richtlinien eingehalten, schützte ihn nicht vor dem Vorhalt, zu viele Verordnungen, nämlich bei zu vielen Patienten, getätigt zu haben.

Bundessozialgericht, Urteil vom 21.03.2012, AZ: B 6 KA 18/11 R.

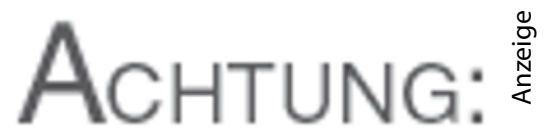

\section{Hier muss de Dummy durcl

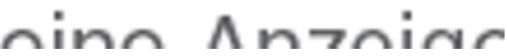

gehen. Ausländische Absolventen deutscher Hochschulen dürfen künftig $18 \mathrm{Mo-}$ nate lang statt bisher 12 Monate nach einer Beschäftigung suchen (s. dazu S. 9).

\section{MMW Kommentar}

Diese Neuregelung könnte nicht nur den sich in Deutschland immer drohender entwickelnden Ärztemangel kompensieren, sondern für inländische Ärzte auch die Chance erhöhen, nach Erreichen der Altersgrenze die eigene Praxis zu veräußern. In vielen KV-Bereichen gibt es diesbezüglich bereits von den Landesregierungen finanziell unterstützte Niederlassungsfördermaßnahmen, die auch von ausländischen Ärzten genutzt werden könnten. 